\title{
Hypophysiotropic Gonadotropin-Releasing Hormone Projections Are Exposed to Dense Plexuses of Kisspeptin, Neurokinin B and Substance $P$ Immunoreactive Fibers in the Human: A Study on Tissues from Postmenopausal Women
}

\author{
Beáta Á. Borsay ${ }^{a}$ Katalin Skrapits $^{\text {b }}$ László Herczeg $^{\text {a }}$ Philippe Ciofi $^{d}$ \\ Stephen R. Bloom ${ }^{\mathrm{e}}$ Mohammad A. Ghatei ${ }^{\mathrm{e}}$ Waljit S. Dhillo ${ }^{\mathrm{e}}$ Zsolt Liposits $^{\mathrm{b}, \mathrm{c}}$ \\ Erik Hrabovszky ${ }^{b}$ \\ ${ }^{a}$ Department of Forensic Medicine, Faculty of Medicine of the University of Debrecen, Debrecen, ${ }^{b}$ Laboratory of \\ Endocrine Neurobiology, Institute of Experimental Medicine, Hungarian Academy of Sciences, and ${ }^{\mathrm{C} D e p a r t m e n t}$ of \\ Neuroscience, Faculty of Information Technology, Pázmány Péter Catholic University, Budapest, Hungary; ${ }^{\text {dINSERM }}$ \\ U862, Neurocentre Magendie, Bordeaux, France; ${ }^{e}$ Department of Investigative Medicine, Hammersmith Hospital, \\ Imperial College London, London, UK
}

\section{Key Words}

Human - Hypothalamus - Infundibulum - Median eminence · Pituitary $\cdot$ Reproduction $\cdot$ Tachykinins

\begin{abstract}
Neuronal populations that synthesize kisspeptin (KP), neurokinin $B(N K B)$ and substance $P(S P)$ in the hypothalamic infundibular nucleus of humans are partly overlapping. These cells are important upstream regulators of gonadotropin-releasing hormone $(\mathrm{GnRH})$ neurosecretion. Homologous neurons in laboratory animals are thought to modulate episodic $\mathrm{GnRH}$ secretion primarily via influencing KP receptors on the hypophysiotropic fiber projections of GnRH neurons. To explore the structural basis of this putative axo-axonal communication in humans, we analyzed the anatomical relationship of KP-immunoreactive (IR), NKB-IR and SP-IR axon plexuses with hypophysiotropic $\mathrm{GnRH}$ fiber projections. Immunohistochemical studies were carried out on histological samples from postmenopausal women. The neuropeptide-IR axons in-
\end{abstract}

nervated densely the portal capillary network in the postinfundibular eminence. Subsets of the fibers formed descending tracts in the infundibular stalk, some reaching the neurohypophysis. KP-IR, NKB-IR and SP-IR plexuses intermingled, and established occasional contacts, with hypophysiotropic $\mathrm{GnRH}$ fibers in the postinfundibular eminence and through their lengthy course while descending within the infundibular stalk. Triple-immunofluorescent studies also revealed considerable overlap between the KP, NKB and SP signals in individual fibers, providing evidence that these peptidergic projections arise from neurons of the mediobasal hypothalamus. These neuroanatomical observations indicate that the hypophysiotropic projections of human GnRH neurons in the postinfundibular eminence and the descending GnRH tract coursing through the infundibular stalk to the neurohypophysis are exposed to neurotransmitters/neuropeptides released by dense KP-IR, NKB-IR and SP-IR fiber plexuses. Localization and characterization of axonal neuropeptide receptors will be required to clarify the putative autocrine and paracrine interactions in these anatomical regions.

(c) 2014 S. Karger AG, Basel

\section{KARGER}

E-Mail karger@karger.com

www.karger.com/nen (c) 2014 S. Karger AG, Basel

0028-3835/14/1003-0141\$39.50/0
Erik Hrabovszky, MD, DS

Department of Endocrine Neurobiology

Institute of Experimental Medicine, Hungarian Academy of Sciences

43 Szigony St., HU-1083 Budapest (Hungary)

E-Mail hrabovszky.erik@koki.hu 


\section{Introduction}

A peptidergic neuron population identified in the hypothalamic arcuate nucleus (ARC) co-synthesizes kisspeptin (KP), neurokinin B (NKB) and dynorphin [1-3] in a variety of mammalian species; these 'KNDy neurons' [4] were proposed to constitute an important regulatory component of the pulse generator which shapes the episodic secretion of gonadotropin-releasing hormone $(\mathrm{GnRH})$ into the hypophysial portal circulation $[2,3,5]$. While homologous KP and NKB neurons are also present in the human infundibular nucleus [6,7], species differences are also likely to exist in the neurotransmitter complement that these neurons use for communication [8]. Notably, morphological studies have found only poor evidence for dynorphin expression in KP-immunoreactive (IR) neurons in the infundibular nucleus of young men [9]. On the other hand, substance P (SP) has been revealed in considerable subsets of KP and NKB neurons in the human [10], but not in the rodent or sheep, KNDy neurons.

The regulation of $\mathrm{GnRH}$ release by overlapping populations of KP and NKB neurons is thought to take place primarily via KP signaling through the KP receptor (KISS1R) which is expressed in GnRH cells [11-13]. While additional immunohistochemical evidence from rats [14] and single-cell microarray evidence from mice [12] indicate that a subset of GnRH neurons also contain the NK3 receptor for NKB, NK3 immunoreactivity has not been revealed in GnRH neurons of the sheep [15]. In addition, the effect of $\mathrm{NKB}$ on $\mathrm{LH}$ release seems to require $\mathrm{KP}$ signaling in the monkey [16], raising further the possibility of species difference. The issue of whether GnRH neurons possess the NK1 receptor for SP has not been addressed.

Hypothalamic KP neurons are capable of regulating reproduction via acting on the somatodendritic compartment of the GnRH cell. Accordingly, GnRH neurons receive KP-IR afferent contacts [7, 17-20] and show depolarization $[12,21,22]$ and cFos expression $[11,23]$ in response to KP. Similarly to KP fibers, NKB-IR axons also establish axo-somatic and axo-dendritic contacts with GnRH neurons in rats [24], mice [25] and humans $[9,26,27]$ and $16 \%$ of the GnRH-IR perikarya in the preoptic area of the rat exhibit NK3 immunoreactivity [14]. Somewhat conflictingly, mouse GnRH neurons do not give electrophysiological responses to the NK3 receptor agonist senktide in slice preparations [28], and senktide does not induce $\mathrm{GnRH}$ release from the preoptic area which contains the GnRH cell bodies [29]. In the human mediobasal hypothalamus, many SP-IR neurons are identical with KP and NKB neurons [10]. SP neurons provide axo-somatic and axo-dendritic inputs to $\mathrm{GnRH}$ neurons, as indicated by light microscopic immunohistochemical observations in humans [30] and immunoelectronmicroscopic data from rats [31].

In addition to influencing the somatic and dendritic compartments of $\mathrm{GnRH}$ neurons, there is accumulating evidence from a variety of species that KP and NKB can also regulate $\mathrm{GnRH}$ secretion in the median eminence, where GnRH axon terminals are juxtaposed to KP-IR [7, $19,32]$ and NKB-IR $[14,33]$ processes. Such direct axoaxonal contacts are devoid of classical synaptic specializations at the ultrastructural level $[32,33]$. Although immunohistochemical studies are still unavailable to demonstrate the presence of the KP receptor (KISS1R) at this putative axo-axonal communication site, a previous immunofluorescence study on rats identified NK3 immunoreactivity on GnRH-IR fibers in the median eminence [14]. Abundant functional evidence exists to support the concept that both KP and NKB act on the axonal compartment of GnRH neurons. Accordingly, GnRH secretion from mediobasal hypothalamic explants of mice (which contain the hypophysiotropic GnRH axons but few if any GnRH cell bodies) can be stimulated by KP in a KISS1R-dependent and action potential-independent manner [34]. A site for KP action outside the blood-brain barrier gains additional support from the observations that systemic KP injection induces $\mathrm{LH}$ secretion in rats $[23,35]$, monkeys [36] and humans [37, 38], although it remains possible that KP causes these effects in other circumventricular organs, including the organum vasculosum of the lamina terminalis [39]. Similarly to KP, the NK3 agonist senktide is capable of eliciting GnRH release from the median eminence of mice and this action does not require KP signaling [29].

In different species, the GnRH pulse generator is thought to be located in the mediobasal hypothalamus which also contains the KNDy neurons. Accordingly, mediobasal hypothalamic explants from fetal and adult human brains release $\mathrm{GnRH}$ in a pulsatile manner [40]. Similarly, GnRH secretion occurs episodically from mediobasal hypothalamic explants of the rat. In this rodent species, the mediobasal hypothalamus contains the hypophysiotropic $\mathrm{GnRH}$ axon projections but no $\mathrm{GnRH}$ cell bodies [41], suggesting that upstream elements of the GnRH pulse generator act via influencing the neurosecretory output of hypophysiotropic GnRH fibers. Information accumulated about KNDy neurons in the last few years has been incorporated into new models of the GnRH/LH pulse generator. According to these models, 
the peptidergic communication of KNDy neurons with each other and with GnRH neurons is critically involved in the regulation of pulsatile GnRH secretion $[3,4,28,42]$.

Here, we have used immunohistochemistry to study the putative axo-axonal interaction sites, where KP-IR and NKB-IR fibers might influence GnRH neurosecretion in the human. The analysis was extended to SP-IR axons, many of which are identical with KP-IR and NKBIR axons in the human [10]. The anatomical relationship of KP-IR [7], NKB-IR [7] and SP-IR [43] axons with GnRH-IR [44] axons was first studied around the postinfundibular eminence which contains the majority of the portal capillaries in the human [45]. GnRH axons in the human and the monkey enter the infundibular stalk (InfS), and many fibers descend all the way down to the neurohypophysis [44]. Therefore, we have also examined the anatomical relationship of these long descending GnRH fiber projections through the InfS to the neurohypophysis with the descending KP-IR, NKB-IR and SP-IR axon tracts.

\section{Materials and Methods}

\section{Tissue Collection}

Human hypothalamic and pituitary tissues from 5 postmenopausal female subjects (53-83 years) were obtained at autopsies [7, 26] from the Forensic Medicine Department of the University of Debrecen, with the permission of the Regional Committee of Science and Research Ethics (DEOEC RKEB/IKEB: 3183-2010). The subjects were not known to suffer from neurological or endocrine disorders and the postmortem intervals before dissection were below $36 \mathrm{~h}$.

\section{Tissue Preparation for Immunohistochemistry}

Brain removal from the skull was carried out in a way to maintain a long pituitary stalk. Dissection guidelines from the hypothalamic blocks were the optic chiasm rostrally, the mammillary bodies caudally and the anterior commissure dorsally $[7,26]$. The hypophysis was also taken out from the sella following the removal of the brain. The tissue blocks were rinsed briefly with running tap water, and then, immersion-fixed in $4 \%$ formaldehyde in $0.1 \mathrm{M}$ phosphate buffered saline ( $\mathrm{pH} 7.4$ ) for 7-21 days. The fixed hypothalami were cut in half before section preparation. The pituitaries and the hemihypothalami were infiltrated with $20 \%$ sucrose for 5 days at $4^{\circ} \mathrm{C}$. The tissues were placed in freezing molds, surrounded with Jung tissue freezing medium (Leica Microsystems, Nussloch $\mathrm{GmbH}$, Germany; diluted 1:1 with $0.9 \%$ sodium chloride solution), snap-frozen on powdered dry ice, and then, sectioned at $30 \mu \mathrm{m}$ with a Leica SM 2000R freezing microtome (Leica Microsystems). The hypothalami were sectioned in the coronal plane and the pituitaries either in the horizontal or the coronal plane. The sections were stored permanently in anti-freeze solution $(30 \%$ ethylene glycol; $25 \%$ glycerol; $0.05 \mathrm{M}$ phosphate buffer; $\mathrm{pH} 7.4$ ) at $-20^{\circ} \mathrm{C}$.

GnRH Fibers as Putative Targets to

Neuropeptide Actions
Tissue Pretreatments

Every 72nd section of the hypothalamic infundibular nucleus (2-3 sections per subject) and the hypophysis was used for each immunohistochemical experiment. The relationship of KP-IR, NKB-IR and SP-IR axons to the portal capillary plexuses and to GnRH-IR fibers was studied on adjacent sections. The sections were rinsed in phosphate buffered saline and pretreated with a mixture of $0.5 \% \mathrm{H}_{2} \mathrm{O}_{2}$ and $0.2 \%$ Triton $\mathrm{X}-100$ for $30 \mathrm{~min}$. Then, epitope retrieval was carried out using a 30 -min treatment in $0.1 \mathrm{M}$ citrate buffer $(\mathrm{pH}=6.0)$ at $80^{\circ} \mathrm{C}$. In immunofluorescent experiments, similar series of sections were used and treated additionally with Sudan black as described previously [46], to reduce tissue autofluorescence [47].

\section{Dual-Labeling Immunohistochemistry}

Incubation of neighboring sections in $\mathrm{KP}, \mathrm{NKB}$ or $\mathrm{SP}$ antibodies for $48 \mathrm{~h}$ at $4^{\circ} \mathrm{C}$ was followed by biotinylated secondary antibodies (Jackson ImmunoResearch Laboratories, West Grove, Pa., USA; 1:500) and the ABC Elite reagent (Vector, Burlingame, Calif., USA; 1:1,000) for 60 min each. The peroxidase signal was visualized with nickel-diaminobenzidine chromogen. Then, the chromogen was silver-gold-intensified as detailed elsewhere [48], except that the thioglycolic acid pretreatment step was left out. KP immunoreactivity was detected with a sheep polyclonal antiserum (GQ2; 1:150,000) against human KP-54. This antiserum recognizes human KP-54, $\mathrm{KP}-14$ and KP-10 and shows no cross-reactivity $(<0.01 \%)$ with other human RF-amide peptides, including prolactin releasing peptide, neuropeptide $\mathrm{FF}$, neuropeptide $\mathrm{AF}$ and RF-amide related peptides (RFRP1, RFRP2, RFRP3) [37]. The GQ2 antibodies were used successfully in previous immunohistochemical experiments on hypothalamic sections from the rhesus monkey $[19,49]$ and the human $[7,9,26,27]$. NKB synthesizing neuronal fibers were visualized with a previously characterized [7, 9, 26, 27, 49] rabbit polyclonal antiserum (IS-682; P. Ciofi; 1:100,000) directed against the C-terminal 28 amino acids of human pro-NKB or alternatively, with a mouse monoclonal antibody against human NKB (Biosensis Pty. Ltd., Thebarton, S.A., Australia; M-871-100; 1:50,000). SP immunoreactivity was detected either with a rat monoclonal antibody (Serotec No. 8450-0505; Bio-Rad Laboratories Inc., Hercules, Calif., USA; $1: 30,000)[10]$ or a rabbit polyclonal antiserum (No. 505D3) raised against the carboxyl terminus of SP (kind gift from Dr. P. Petrusz, Department of Anatomy, University of North Carolina, Chapel Hill, N.C., USA; 1:150,000). This rabbit antiserum required an amidated carboxyl terminus group for recognition and showed less than $0.05 \%$ cross-reactivity with either neurokinin A or NKB [50].

Following the detection of KP, NKB or SP, the sections were processed further to detect GnRH-IR axons, using a previously characterized guinea pig antiserum against mammalian $\mathrm{GnRH}$ (No. 1018; 1:50,000) [26]. GnRH-IR elements were visualized with the biotinylated secondary antibody- $\mathrm{ABC}$ technique and brown diaminobenzidine chromogen, as in previous dual-label immunoperoxidase experiments $[7,9,26,27]$.

\section{Triple-Immunofluorescent Labeling for the Simultaneous}

Visualization of $K P, N K B$ and $S P$

A series of hypothalamic and hypophysial sections was used to study the putative colocalization between KP, NKB and SP immunoreactivities. First, the primary antibodies were applied to the sections in a cocktail consisting of the sheep KP $(1: 1,000)$, rabbit $\operatorname{NKB}(1: 1,000)$ and rat SP $(1: 1,000)$ antibodies $\left(4^{\circ} \mathrm{C} ; 24 \mathrm{~h}\right)$. Then, 
the sections were transferred for $12 \mathrm{~h}$ at $4{ }^{\circ} \mathrm{C}$ into the following secondary antibody cocktail: anti-sheep-Cy3 $(1: 1,000)+$ anti-rabbit-FITC (1:250) + anti-rat-Cy5 (1:500).

\section{Section Mounting and Coverslipping}

Sections processed with peroxidase-based immunohistochemistry were mounted on microscope slides from Elvanol, air-dried, dehydrated with $95 \%$ ( $5 \mathrm{~min})$, followed by $100 \%(2 \times 5 \mathrm{~min})$ ethanol, cleared with xylene $(2 \times 5 \mathrm{~min})$ and coverslipped with DPX mounting medium (Sigma, St. Louis, Mo., USA). Immunofluorescent specimens were mounted from $0.1 \mathrm{M}$ Tris-HCl buffer ( $\mathrm{pH} 7.6$ ) and coverslipped with the aqueous mounting medium Mowiol.

\section{Analysis}

Peroxidase-labeled sections were analyzed and representative light microscopic images prepared with an AxioCam MRc 5 digital camera mounted on a Zeiss AxioImager M1 microscope, and using the AxioVision 4.6 software (Carl Zeiss, Göttingen, Germany).

Confocal images from the triple-immunofluorescent specimens were prepared with a Radiance 2100 (Bio-Rad Laboratories, Hemel Hempstead, UK) confocal systems. Individual optical slices $(<0.8 \mu \mathrm{m})$ were collected for analysis and illustrations using the 'lambda strobing' function so that only one excitation laser and the corresponding emission detector were active during a line scan, to eliminate emission crosstalk between the fluorophores. The separately recorded red, green and far-red channels were merged and transferred into the red, blue and green channels of Adobe Photoshop (PSD) files, respectively.

\section{Specificity Controls}

Various control approaches were used to confirm the specificity of immunohistochemical results. For peroxidase-based detection, specificity controls included the comparative analysis of the immunohistochemical staining obtained with two distinct antisera in neighboring sections. In the case of KP, results obtained with the sheep GQ2 antiserum against the processed active peptide KP-54 (amino acids 68-121 of Q15726) and two commercially available affinity-purified rabbit polyclonal antibodies (Antibody Verify Inc., Las Vegas, Nev., USA) were compared. These rabbit reference antibodies target amino acids 21-81 (AAS26420C) and 47-107 (AAS27420C), respectively, of the 138-amino acid human pro-KP sequence (Q15726). Of note, these peptide segments do not include

Fig. 1. Overlapping distribution of GnRH-IR, KP-IR, NKB-IR and SP-IR axons in the postinfundibular eminence, infundibular stalk and neurohypophysis. Dual-immunoperoxidase-stained histological sections of the postinfundibular eminence from postmenopausal women illustrate very dense KP-IR (a-c), NKB-IR (d-f) and SP-IR (g-i) axon plexuses (black silver-gold-intensified nickel-diaminobenzidine chromogen) around the portal capillary vessels. Brown diaminobenzidine labeling reveals the hypophysiotropic $\mathrm{GnRH}$ fiber plexuses that surround the portal vasculature similarly. j-r Not all peptidergic axons terminate in the postinfundibular eminence and considerable subsets descend through the infundibular stalk to reach the neurohypophysis. Note that these descending fibers appear as parallel tracks in $\mathbf{j}$ and $\mathbf{m}$, whereas they are transected in $\mathbf{p}$ due to the different section plane. Arrows in high-power panels point to the occasional axo-axonal contacts es- the C-terminal RF-amide motif of KP which could account for unwanted cross-reactions with other members of the RF-amide peptide family. For NKB, results obtained with the rabbit antisera (IS681 and IS-682) [7] and with the mouse monoclonal antibody (M871-100) were compared. Similar positive control experiments for SP labeling were carried out by replicating the immunohistochemical labeling with the rabbit (No. 505D3) and the rat (No. 84500505) antibodies. Negative control experiments included the omission of the primary or secondary antibodies from the labeling procedure.

In triple-label immunofluorescent studies, the presence of many bright single-labeled, in addition to double- and triple-labeled, structures served as an endogenous control for the absence of antibody cross-reactions and bleed-through.

Finally, series of test sections were dual-labeled with the combined use of the rabbit and sheep KP antibodies, the rabbit and mouse NKB antibodies or the rabbit and rat SP antibodies. In these double-labeling experiments, the primary antibodies raised in the different species were detected with FITC-conjugated and Cy3conjugated secondary antibodies.

\section{Results}

\section{Demonstration of Anatomical Overlap between}

Hypophysiotropic GnRH Fibers and Axons Expressing $K P, N K B$, and SP Immunoreactivities

The hypothalamic distribution of GnRH-IR [44, 51, 52], KP-IR [7, 8], NKB-IR [7] and SP-IR [30, 43] neuronal cell bodies and fibers was in agreement with previous reports. While the dual-labeling experiments confirmed that GnRH neurons in the mediobasal hypothalamus receive axo-somatic and axo-dendritic afferent contacts from KP-IR, NKB-IR and SP-IR neurons [7, 26, 30], the present study focused on the anatomical sites of major hypophysiotropic GnRH fiber projections. These GnRH projections were present in highest abundance in the postinfundibular eminence (fig. 1a-i) which contains a

tablished by KP-IR, NKB-IR and SP-IR axons with GnRH-IR fibers in the postinfundibular eminence $(\mathbf{b}, \mathbf{c}, \mathbf{e}, \mathbf{f}, \mathbf{h}, \mathbf{i})$ and the neurohypophysis $(\mathbf{k}, \mathbf{I}, \mathbf{n}, \mathbf{o}, \mathbf{q}, \mathbf{r})$. s, $\mathbf{t}$ Results of triple-immunofluorescent studies provide evidence that KP-IR (red), NKB-IR (blue) and SP-IR (green) fibers involved in the putative axo-axonal interactions with $\mathrm{GnRH}$ fibers are often identical. Colocalization of the neuropeptides also indicates that these fibers originate in the infundibular nucleus. White color in the infundibular stalk (s) and in the neurohypophysis (t) corresponds to fibers that contain all three fluorochromes. t Arrowheads point to triple-labeled (KP/ $\mathrm{NKB} / \mathrm{SP}-\mathrm{IR}$ ) axon varicosities the neurohypophysis, whereas many single- and double-labeled (NKB/SP: turquoise; SP/KP: yellow; KP/NKB: purple) fibers also occur. Scale bar in $\mathbf{t}$ corresponds to $60 \mu \mathrm{m}$ in $\mathbf{a}, \mathbf{d}, \mathbf{g}, 10 \mu \mathrm{m}$ in $\mathbf{b}, \mathbf{c}, \mathbf{e}, \mathbf{f}, \mathbf{h}, \mathbf{k}, \mathbf{I}, \mathbf{n}, \mathbf{o}, \mathbf{q}, \mathbf{r}, 30 \mu \mathrm{m}$ in $\mathbf{s}$ and $6 \mu \mathrm{m}$ in $\mathbf{t}$.

(For figure see next page.) 


\section{postinfundibular eminence}
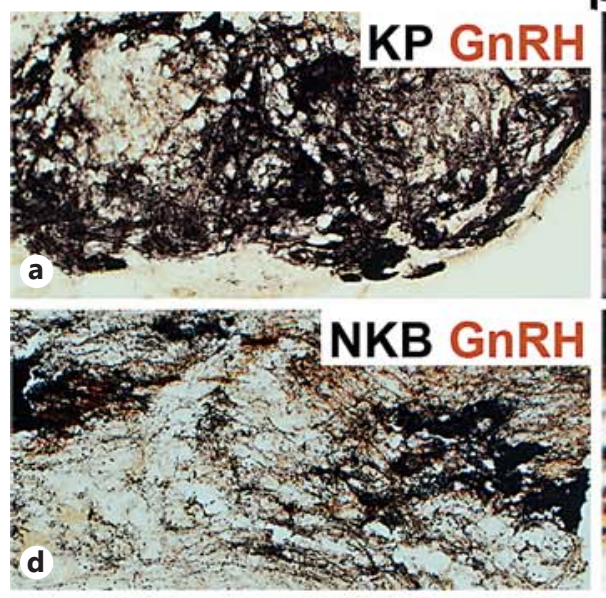

b.
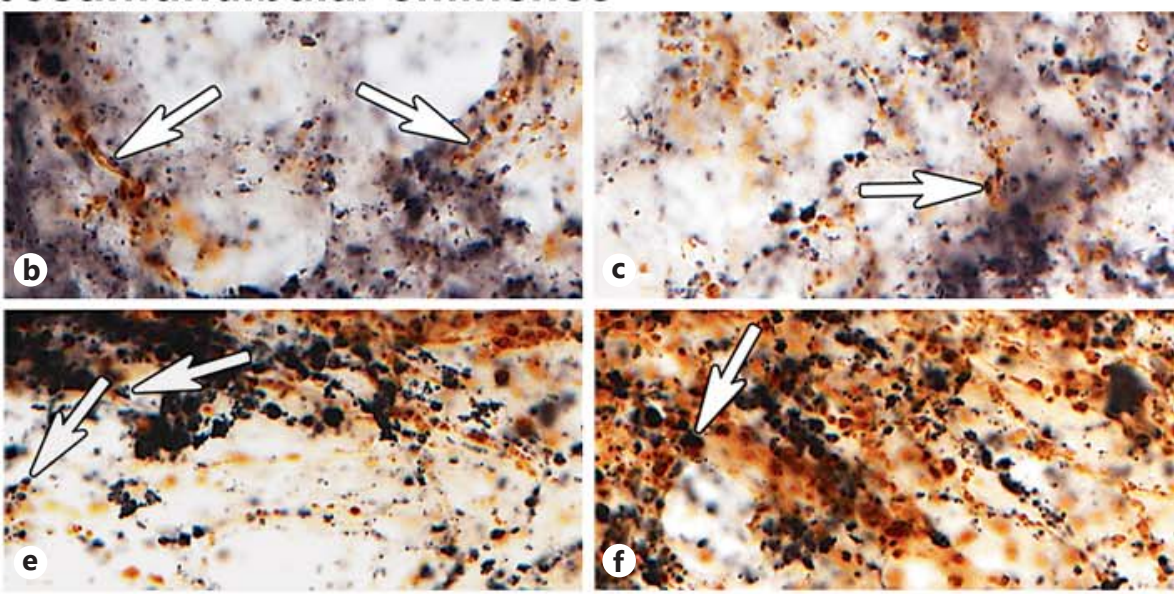

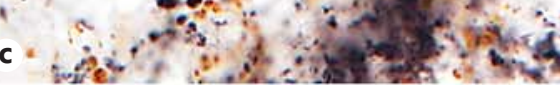

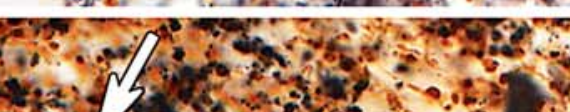

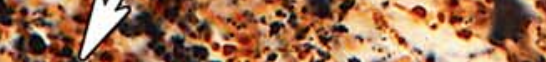

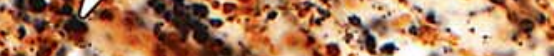

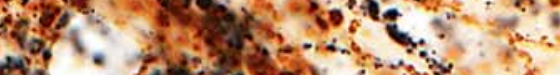

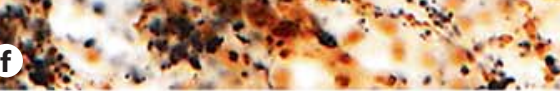

\section{c. SP GnRH}
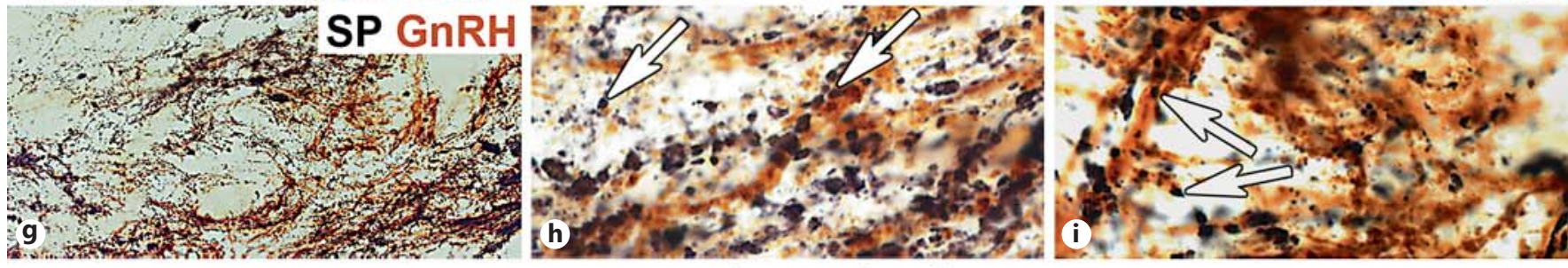

\section{neurohypophysis}
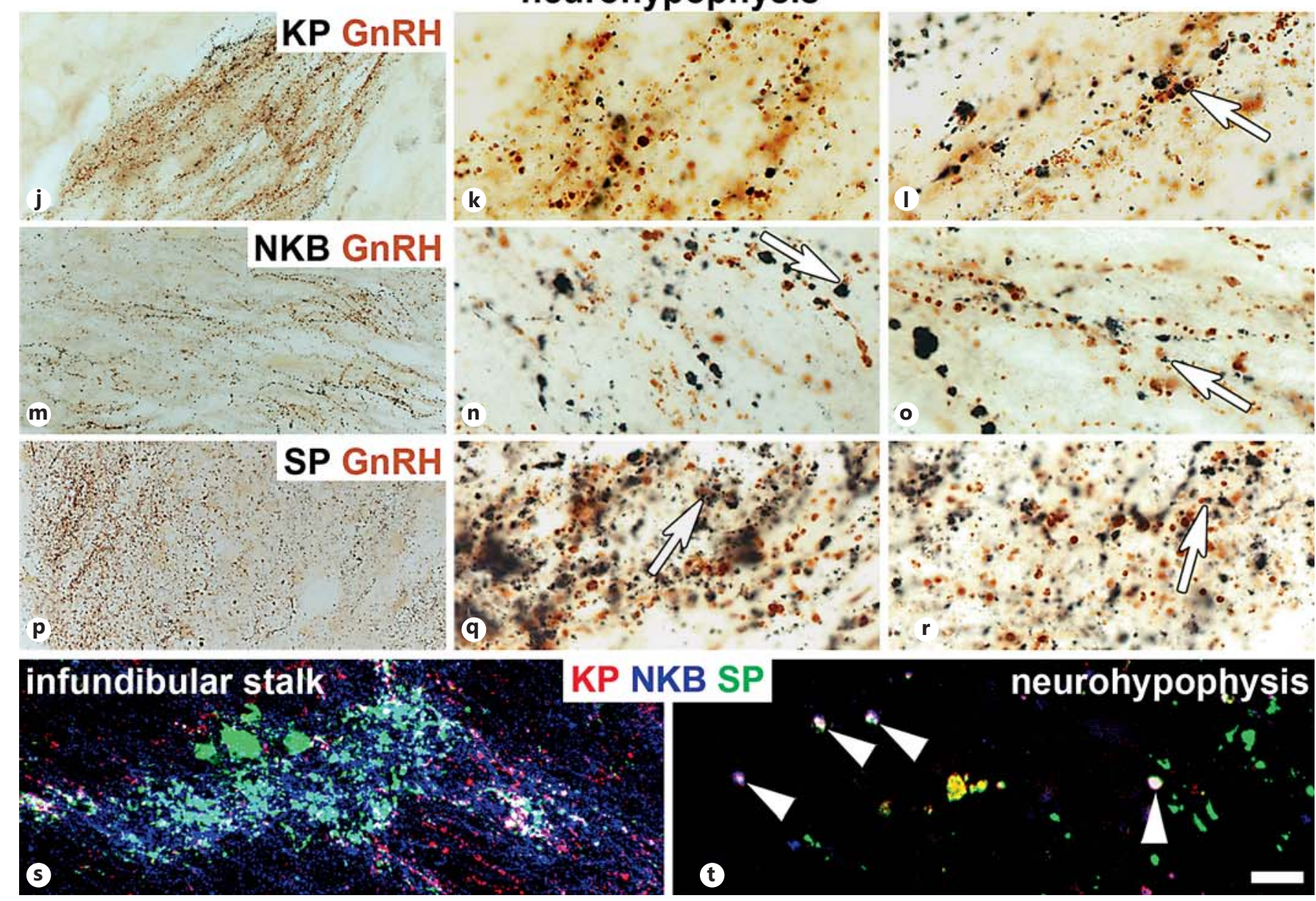

is:

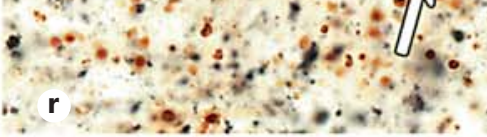

KB SP

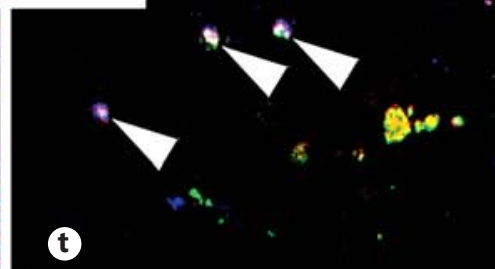

neurohypophysis

GnRH Fibers as Putative Targets to

Neuroendocrinology 2014;100:141-152

145

Neuropeptide Actions 
superficial and a deep plexus of hypophysial portal capillaries [45]. These capillary plexuses were surrounded by GnRH-IR axons and, at the same time, also by very dense KP-IR (fig. 1a), NKB-IR (fig. 1d) and SP-IR (fig. 1g) fiber networks. High-power light microscopic analysis of double-labeled sections revealed occasional axo-axonal appositions between the GnRH-IR fibers and the other three phenotypes of peptidergic axons (fig. $1 \mathrm{~b}, \mathrm{c}, \mathrm{e}, \mathrm{f}, \mathrm{h}, \mathrm{i}$ ).

The analysis of immunostained histological sections from the neurohypophysis confirmed the previous observation [44] that a significant population of GnRH-IR fibers entering the human InfS descend to the neurohypophysis (fig. $1 j-r$ ). In addition, we found that the neurohypophysis also contained abundant plexuses of KP-IR (fig. 1j-l), NKB-IR (fig. 1m-o) and SP-IR (fig. 1p-r) fibers; the course and distribution of these fibers overlapped with the projection areas of the descending $\mathrm{GnRH}$ IR processes (fig. 1k, l, n, o, q, r). In each dual-labeling experiment, occasional axo-axonal contacts were also detectable between the different types of peptidergic axons and the GnRH fibers (fig. 1l, n, o, q, r).

\section{Visualization of the Parallel Descent of GnRH-IR and} SP-IR Fibers through the InfS

Some hypothalamic samples contained long InfS, allowing us to follow the parallel descent of different peptidergic projections (fig. 2). The analysis of such specimens showed that peptidergic axons often intermingled with groups of IR cell bodies, in particular in the upper portions of the InfS (fig. 2c-e). The descending KP-IR, NKB-IR and SP-IR axon tracts intermingled and established sporadic axo-axonal contacts with the GnRH-IR fibers (fig. 2b, f).

\section{Colocalization of KP, NKB and SP Immunoreactivities} in Peptidergic Axons

Triple-immunofluorescent studies revealed colocalization between KP (red), NKB (blue) and SP (green) immunoreactivities in individual axons in the InfS (fig. 1s) and the neurohypophysis (fig. 1t). Notably, the colocalization was only partial; single- and double-labeled (NKB/

Fig. 2. Simultaneous immunohistochemical visualization of SPIR and GnRH-IR descending fibers in the infundibular stalk of a postmenopausal woman. a A coronal hemihypothalamic section of a postmenopausal woman through the long infundibular stalk has been dual-immunostained for SP (black silver-gold-intensified nickel-diaminobenzidine chromogen) and GnRH (brown diaminobenzidine). $3 \mathrm{~V}=$ Third ventricle. Note that the dense longitudinal plexuses of SP-IR and GnRH-IR axons intermingle
SP: turquoise; SP/KP: yellow; KP/NKB: purple) fibers occurred more frequently than the triple-labeled (white color) ones (fig. 1s, t).

\section{Dual-Immunofluorescent Control Experiments}

to Verify the Specificity of KP, NKB and SP

\section{Immunolabeling}

The combined use of two different primary antibodies (raised in different species) for immunofluorescent duallabeling showed that the different KP, NKB and SP antibodies label essentially identical neuronal structures; the majority of IR neuronal elements appear to be dual-labeled (fig. 3a-1), in strong support of labeling specificity.

\section{Discussion}

In this study, we present morphological evidence that hypophysiotropic GnRH axons in postmenopausal women form intermingling plexuses and establish occasional axoaxonal appositions with KP-IR, NKB-IR and SP-IR fibers. Such areas of regional overlap and axo-axonal contacts were detected throughout the lengthy course of the hypophysiotropic GnRH axons, including the postinfundibular eminence, the InfS and the neurohypophysis. We also show that many of the KP-IR, NKB-IR and SP-IR fibers in these regions are identical, indicating that their site of origin is the infundibular nucleus, where a subsets of neurons cosynthesize two or all three of these neuropeptides [10].

Comparative analysis of the $\mathrm{GnRH}$ neuronal system in humans, monkeys, ferrets, bats and rats revealed conspicuous species differences regarding the course of hypophysiotropic GnRH axon projections. Unlike in rats, where these fibers terminate in the palisade zone of the median eminence, considerable subsets of GnRH-IR axons in the human and the monkey also enter the internal zone of the InfS and even descend to the neurohypophysis [44]. A previous dual-label immunohistochemical study in the monkey revealed that the descending GnRHIR axon projections and a descending KP-IR axon plexus intermingle in the posterior pituitary [53]. In our present

and descend deeply into the stalk, some reaching the neurohypophysis. c-e As shown in high-power insets, the descending fibers often intermingle with groups of neuronal cell bodies. b, $\mathbf{f}$ Arrows point to the sporadic axo-axonal contacts between SP-IR and GnRH-IR axons which may underlie putative paracrine interactions. Scale bar in $\mathbf{f}$ corresponds to $420 \mu \mathrm{m}$ in $\mathbf{a}$ and $10 \mu \mathrm{m}$ in $\mathbf{b}-\mathbf{f}$.

(For figure see next page.)
Borsay/Skrapits/Herczeg/Ciofi/Bloom/ Ghatei/Dhillo/Liposits/Hrabovszky 


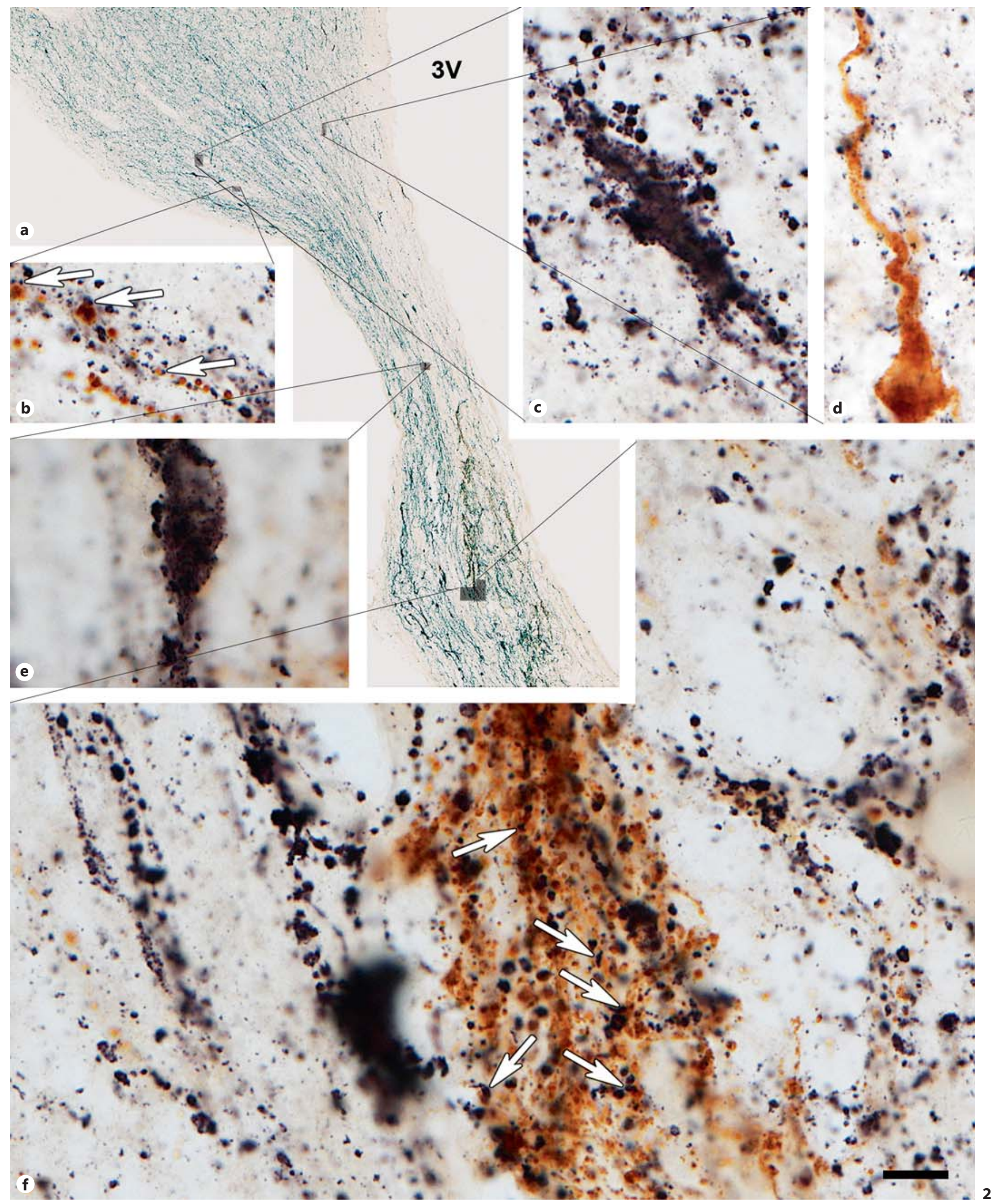

GnRH Fibers as Putative Targets to

Neuroendocrinology 2014;100:141-152

147 

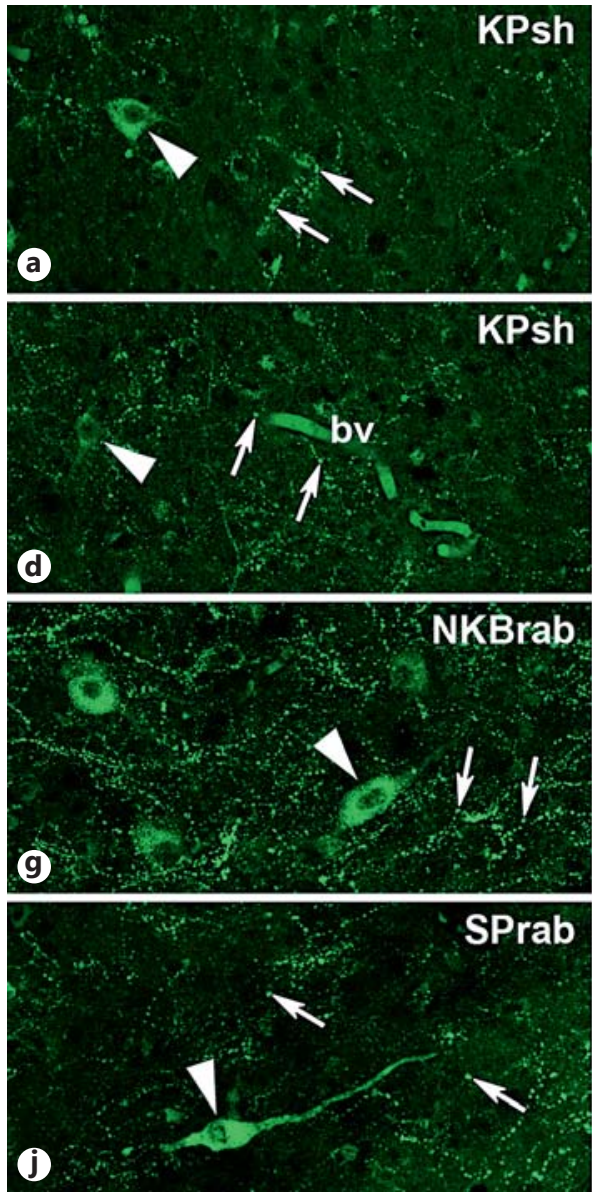
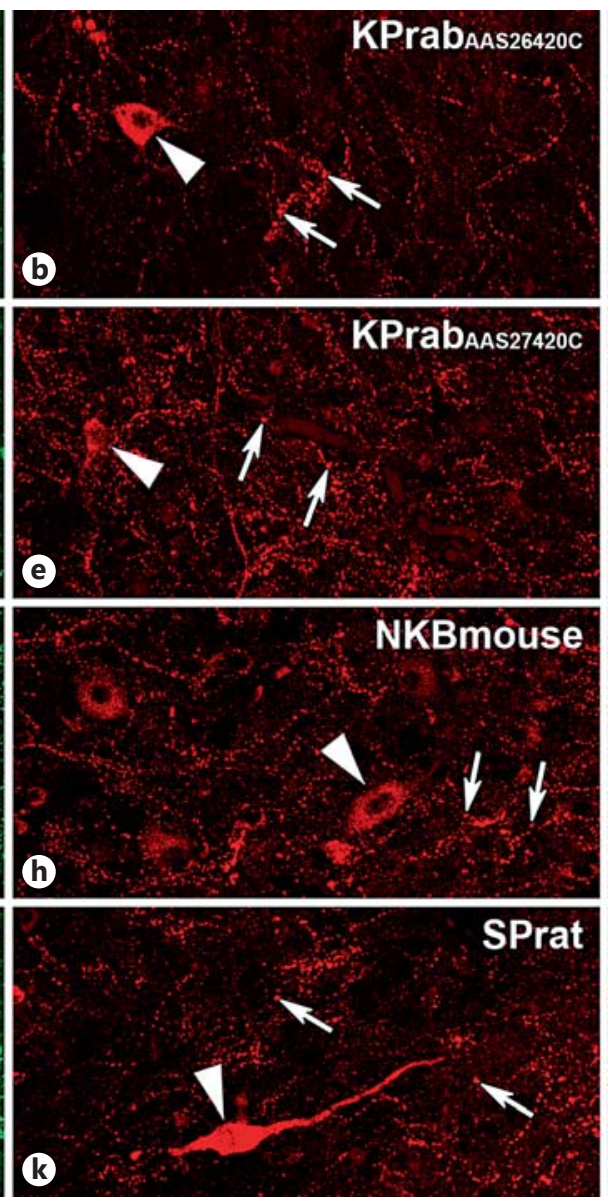
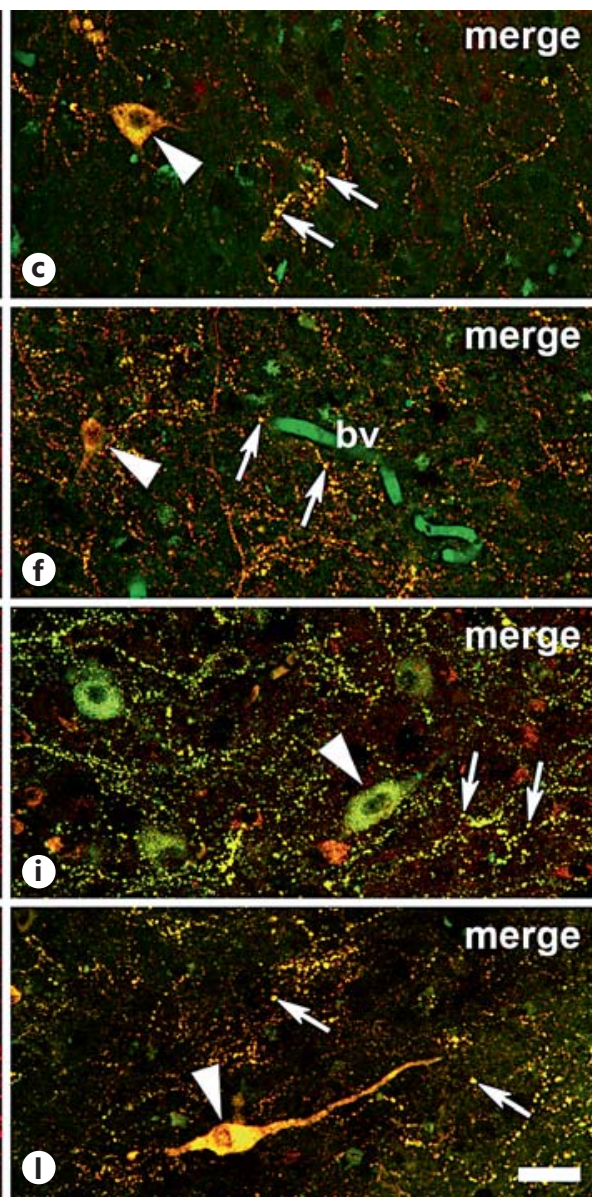

Fig. 3. Results of positive control experiments using pairs of antibodies raised in two different animal species against the same neuropeptide target. The specificity of labeling with the KP (GQ2; a, d), NKB (IS-682; g) and SP (No. 505D3; j) antisera has been challenged in dual-immunofluorescent experiments using other reference KP (AAS26420C and AAS27420C; b, e, respectively), NKB (M-871-100; h) and SP (No. 8450-0505; k) antibodies, respectively. The two primary antibodies used in combination were reacted with secondary antibodies conjugated with Cy3 and FITC, respectively. Results of these control experiments indicate that the vast majority of cell bodies and fibers in the infundibular nucleus can be dual-labeled (yellow color in the merged images $\mathbf{c}, \mathbf{f}, \mathbf{i}$ and
I) with the red $\mathrm{Cy} 3$ and the green FITC chromogens. The specificity of labeling with the GQ2 antibodies against the processed active peptide KP-54 (amino acids 68-121 of Q15726; a, d) has been verified with two distinct commercial antibodies against the 138-amino acid human pro-KP protein (Q15726). These affinity-purified reference antibodies target amino acids 21-81 (AAS26420C; b) and 47-107 (AAS27420C; e), respectively. Dual-labeled cell bodies are indicated by arrowheads and dual-labeled axon varicosities by arrows in 0.8- $\mu \mathrm{m}$-thick optical slices. bv = Blood vessel exhibiting green autofluorescence. Scale bar in I corresponds to $35 \mu \mathrm{m}$ in all panels. study, we provide evidence that $\mathrm{GnRH}$ fibers in the human are accompanied by dense KP-IR, NKB-IR and SPIR fiber plexuses in the postinfundibular eminence as well as throughout their lengthy course to the neurohypophysis. Occasional contacts could also be identified between these and GnRH-IR fibers in all of these regions. The close anatomical relationship of these peptidergic plexuses may allow important paracrine interactions to occur at the level of the axonal compartments. The functional importance of the massive descending peptidergic fiber projections toward the neurohypophysis requires clarification. It is possible that neuropeptides released from the varicosities of these axon plexuses reach the adenohypophysis via the short portal veins to influence gonadotroph functions. In addition, the secreted neuropeptides might directly enter the systemic circulation from the portal capillary plexuses of the postinfundibular eminence [45] and through the tuberal veins of the InfS. It is important to recognize that many neuropeptides present in the external zone of the sheep median eminence are not 
necessarily secreted in significant amounts into the hypophysial portal blood [54] and this can also be the case in primates.

A recent study from our laboratory established that many of the KP-IR, NB-IR and SP-IR cell bodies and lower subsets of axons in the human mediobasal hypothalamus are identical, with the largest degrees of neuropeptide coexpression observed in postmenopausal women [10]; in this endocrine status, $25.1 \%$ of the NKB-IR and $30.6 \%$ of the KP-IR perikarya contained SP and $16.5 \%$ of all immunolabeled cell bodies were triple-labeled [10]. In the present study, we observed many single- and double-labeled KP-IR, NKB-IR and SP-IR fibers both in the infundibular nucleus and the InfS. The much lower degree of signal coexpression in axons versus cell bodies implies that many fibers derived from $\mathrm{KP} / \mathrm{NKB} / \mathrm{SP}$ neurons only contain one or two neuropeptides in postmenopausal women. This observation raises the possibility that the axonal transport, processing and use for neurotransmission of the co-synthesized neuropeptides might be regulated depending on the functional status of these neurons. Earlier studies of the human KP and NKB systems in our laboratory already provided evidence that the extent of colocalization between KP and NKB is sex dependent $[8,26]$ and also age dependent, at least in men $[8,27]$. In addition to this difference in the labeling of perikarya, we noticed that the neuronal contacts that these cells establish with $\mathrm{GnRH}$ neurons exhibit sex-specific patterns of KP/NKB co-labeling, with a significantly higher incidence of double-labeled fibers in postmenopausal women compared with age-matched men [26]. It will be important in the future to determine how the reproductive status influences neuropeptide colocalization in the axon projections of these neurons, including the plexuses we propose here to interact with the hypophysiotropic $\mathrm{GnRH}$ fiber projections via autocrine/paracrine peptidergic mechanisms. At present, it is impossible to determine whether or not the occasionally observed axo-axonal contacts play a significant role in this putative axo-axonal interaction.

Axo-axonal interactions taking place in the median eminence/postinfundibular eminence region have long been thought to play important roles in neuroendocrine regulation [55]. However, it is difficult to appreciate the functional significance of this putative paracrine communication only on the basis of morphological studies, given that synaptic specializations are absent from such axoaxonal contacts at the ultrastructural level $[33,56]$. While the immunohistochemical demonstration of specific receptors on neuroendocrine GnRH terminals would be indicative of such a paracrine communication, the evidence

GnRH Fibers as Putative Targets to

Neuropeptide Actions for axo-axonal interactions is mostly indirect and comes from functional studies. Because in rats, the mediobasal hypothalamus is devoid of GnRH-IR cell bodies and only contains hypophysiotropic projections [57], in vitro explants of this region can be used in pharmacological studies of receptor interactions that might influence $\mathrm{GnRH}$ secretion at the level of the GnRH axon. For example, GnRH terminals in the median eminence of the rat are juxtaposed to glutamatergic axons $[56,58]$ and express immunoreactivity for the KA2 and NR1 ionotropic glutamate receptor subunits [56]. There is in vitro evidence that glutamatergic drugs can induce $\mathrm{Ca}^{2+}$-dependent $\mathrm{GnRH}$ release from median eminence fragments in a Cadependent manner [59]. It is interesting to note that the source of glutamate in this interaction may be, at least partly, intrinsic, since GnRH neurons of the adult male rat exhibit glutamatergic properties and express type 2 vesicular glutamate transporter $\mathrm{mRNA}$ and immunoreactivity [60]. Neuropeptide Y (NPY) also appears to act similarly on the GnRH axon terminals, in addition to occurring in axons that form axo-somatic and axo-dendritic contacts onto GnRH neurons of rats and humans [51, 61]. In rats, (a) direct appositions exist between NPY-IR and GnRH-IR axons in the median eminence [62], (b) $\mathrm{GnRH}$ axon terminals express $\mathrm{Y} 1$ receptor immunoreactivity [62] and (c) NPY agonists stimulate in vitro GnRH release from median eminence fragments [63].

While the putative presence of KISS1R on GnRH terminals has not been detected formally with immunohistochemistry, there is abundant indirect evidence to support the concept that GnRH terminals represent important physiological sites of KP action in the regulation of pulsatile GnRH secretion. Accordingly, KP-IR axons are intimately juxtaposed to GnRH-IR axons in the goat [32], monkey [19] and human [7] median eminence, and KP can stimulate $\mathrm{GnRH}$ release from median eminence fragments of wild-type, but not KISS1R mutant, mice [34]. This in vitro action of KP is independent of action potential generation, and thus persists in the presence of tetrodotoxin [34]. Axo-axonal communication may represent the primary mechanism, whereby KNDy neurons influence the pulsatile secretion of GnRH. Accordingly, KP release into the monkey median eminence was found to be pulsatile, with secretory peaks that coincide with the LH pulses [64]. Furthermore, the proposed axonal site of action for KP is in accordance with the observation that the peripheral injection of KP results in rapid increases of LH release [23, 35, 36, 65] which can be prevented with the GnRH antagonist acylin [65]. KP is likely to influence GnRH neurons outside the blood-brain barrier because it 
does not induce c-fos expression in GnRH cell nuclei of the preoptic area. We have to recognize that systemic KP may also act in other circumventricular organs lacking the blood-brain barrier, including the organum vasculosum of the lamina terminalis. In this context, it is important to mention that recent neuroanatomical studies of the mouse organum vasculosum of the lamina terminalis identified GnRH-IR processes with dendritic characteristics and extensive branching. Direct application of KP onto these processes caused electric activity and c-Fos expression in GnRH neurons [39]. We note that the GnRHIR innervation of the human OVLT is much less abundant in comparison with the rodent [44]; therefore, it seems more likely that the LH release induced by systemic KP injection in humans $[37,38]$ is caused by the excitation of hypophysiotropic GnRH axons.

The present study also provided evidence for the regional overlap and axo-axonal contacts between NKB-IR and GnRH-IR axons. Similar appositions are also detectable in the rat median eminence [14,33], where the GnRHIR axons express immunoreactivity for the NKB receptor NK3 [14]. While recent models of the GnRH pulse generator agree in that KP provides the major output signal of the putative pacemaker KNDy neurons toward the GnRH network [2,3], whether or not NKB can also regulate the release of $\mathrm{GnRH}$ directly, remains to be established. Given that NK3 is present in KNDy neurons and the NK3 agonist senktide excites KP neurons but not GnRH neurons [28], NKB/NK3 signaling might mainly act in the intranuclear communication of KNDy neurons within the network. It is possible that NKB can also regulate NKB axon terminals in the median eminence. In addition to exerting autocrine/paracrine actions on other KP and NKB neurons, recent studies on mice found evidence that senktide is capable of inducing $\mathrm{GnRH}$ release directly from the median eminence, and this action does not require KP signaling [29]. Of note, species might considerably differ in this context, and the role of KP seems to be essential for the NKB-mediated GnRH release in rhesus monkeys [16]. SP is a recently recognized neuropeptide player in the putative pulse generator KP and NKB neuronal systems. It will require clarification whether SP acts via influencing $\mathrm{GnRH}$ axon terminals directly or via regulating neuropeptide release from other types of fibers through autocrine/paracrine mechanisms.

In summary, in this study we provide evidence that the hypophysiotropic projections of human $\mathrm{GnRH}$ neurons are exposed to KP, NKB and SP in the postinfundibular eminence as well as throughout their lengthy descending projection pathway through the InfS to the neurohypophysis. Depending on the site/s of location of the SP receptor NK1, the NKB receptor NK3 and the KP receptor KISS1R, the proposed axo-axonal interaction may involve important autocrine and paracrine components. To fully understand these mechanisms, information about the cellular and subcellular localization of the neuropeptide receptors will be critical.

\section{Acknowledgements}

The research leading to these results has received funding from the National Science Foundation of Hungary (OTKA K83710, K100722, K112669), the National Development Agency (BONUS HU 08/2-2011-0006) and the European Community's Seventh Framework Programme (FP7/2007-2013) under grant agreement No. 245009. WSD is funded by an NIHR Career Development Fellowship. We thank Ms. Hajni Bekó for expert technical assistance and Dr. Péter Petrusz for the rabbit SP antiserum.

\section{References}

1 Goodman RL, Lehman MN, Smith JT, Coolen LM, de Oliveira CV, Jafarzadehshirazi MR, Pereira A, Iqbal J, Caraty A, Ciofi P, Clarke IJ: Kisspeptin neurons in the arcuate nucleus of the ewe express both dynorphin A and neurokinin B. Endocrinology 2007;148:5752-5760.

2 Navarro VM, Gottsch ML, Chavkin C, Okamura H, Clifton DK, Steiner RA: Regulation of gonadotropin-releasing hormone secretion by kisspeptin/dynorphin/neurokinin B neurons in the arcuate nucleus of the mouse. J Neurosci 2009;29:11859-11866.

- 3 Wakabayashi Y, Nakada T, Murata K, Ohkura S, Mogi K, Navarro VM, Clifton DK, Mori Y, Tsukamura H, Maeda K, Steiner RA, Okamura $\mathrm{H}$ : Neurokinin B and dynorphin A in kisspeptin neurons of the arcuate nucleus participate in generation of periodic oscillation of neural activity driving pulsatile gonadotropin-releasing hormone secretion in the goat. J Neurosci 2010;30:3124-3132.

4 Lehman MN, Coolen LM, Goodman RL: Minireview: kisspeptin/neurokinin B/dynorphin (KNDy) cells of the arcuate nucleus: a central node in the control of gonadotropinreleasing hormone secretion. Endocrinology 2010;151:3479-3489.

5 Ohkura S, Takase K, Matsuyama S, Mogi K, Ichimaru T, Wakabayashi Y, Uenoyama Y, Mori Y, Steiner RA, Tsukamura H, Maeda KI, Okamura H: Gonadotrophin-releasing hormone pulse generator activity in the hypo- thalamus of the goat. J Neuroendocrinol 2009; 21:813-821.

-6 Rometo AM, Krajewski SJ, Voytko ML, Rance NE: Hypertrophy and increased kisspeptin gene expression in the hypothalamic infundibular nucleus of postmenopausal women and ovariectomized monkeys. J Clin Endocrinol Metab 2007;92:2744-2750.

7 Hrabovszky E, Ciofi P, Vida B, Horvath MC, Keller E, Caraty A, Bloom SR, Ghatei MA, Dhillo WS, Liposits Z, Kallo I: The kisspeptin system of the human hypothalamus: sexual dimorphism and relationship with gonadotropin-releasing hormone and neurokinin B neurons. Eur J Neurosci 2010;31: 1984-1998. 
8 Hrabovszky E: Neuroanatomy of the human hypothalamic kisspeptin system. Neuroendocrinology 2014;99:33-48.

-9 Hrabovszky E, Sipos MT, Molnar CS, Ciofi P, Borsay BA, Gergely P, Herczeg L, Bloom SR, Ghatei MA, Dhillo WS, Liposits Z: Low degree of overlap between kisspeptin, neurokinin $B$, and dynorphin immunoreactivities in the infundibular nucleus of young male human subjects challenges the KNDy neuron concept. Endocrinology 2012;153:49784989.

10 Hrabovszky E, Borsay BA, Racz K, Herczeg L, Ciofi P, Bloom SR, Ghatei MA, Dhillo WS, Liposits Z: substance P immunoreactivity exhibits frequent colocalization with kisspeptin and neurokinin $\mathrm{B}$ in the human infundibular region. PLoS One 2013;8:e72369.

11 Irwig MS, Fraley GS, Smith JT, Acohido BV, Popa SM, Cunningham MJ, Gottsch ML, Clifton DK, Steiner RA: Kisspeptin activation of gonadotropin releasing hormone neurons and regulation of kiss- 1 mRNA in the male rat. Neuroendocrinology 2004;80:264-272.

-12 Todman MG, Han SK, Herbison AE: Profiling neurotransmitter receptor expression in mouse gonadotropin-releasing hormone neurons using green fluorescent protein-promoter transgenics and microarrays. Neuroscience 2005;132:703-712.

13 Messager S, Chatzidaki EE, Ma D, Hendrick AG, Zahn D, Dixon J, Thresher RR, Malinge I, Lomet D, Carlton MB, Colledge WH, Caraty A, Aparicio SA: Kisspeptin directly stimulates gonadotropin-releasing hormone release via $G$ protein-coupled receptor 54 . Proc Natl Acad Sci U S A 2005;102:1761-1766.

14 Krajewski SJ, Anderson MJ, Iles-Shih L, Chen KJ, Urbanski HF, Rance NE: Morphologic evidence that neurokinin B modulates gonadotropin-releasing hormone secretion via neurokinin 3 receptors in the rat median eminence. J Comp Neurol 2005;489:372-386.

15 Amstalden M, Coolen LM, Hemmerle AM, Billings HJ, Connors JM, Goodman RL, Lehman MN: Neurokinin 3 receptor immunoreactivity in the septal region, preoptic area and hypothalamus of the female sheep: colocalisation in neurokinin B cells of the arcuate nucleus but not in gonadotrophin-releasing hormone neurones. J Neuroendocrinol 2010;22:1-12.

16 Ramaswamy S, Seminara SB, Plant TM: Evidence from the agonadal juvenile male rhesus monkey (Macaca mulatta) for the view that the action of neurokinin $\mathrm{B}$ to trigger gonadotropin-releasing hormone release is upstream from the kisspeptin receptor. Neuroendocrinology 2011;94:237-245.

-17 Kinoshita M, Tsukamura H, Adachi S, Matsui $H$, Uenoyama $Y$, Iwata $K$, Yamada S, Inoue $K$, Ohtaki T, Matsumoto H, Maeda K: Involvement of central metastin in the regulation of preovulatory luteinizing hormone surge and estrous cyclicity in female rats. Endocrinology 2005; 146:4431-4436

18 Clarkson J, Herbison AE: Postnatal development of kisspeptin neurons in mouse hypo- thalamus; sexual dimorphism and projections to gonadotropin-releasing hormone neurons. Endocrinology 2006;147:5817-5825.

19 Ramaswamy S, Guerriero KA, Gibbs RB, Plant TM: Structural interactions between kisspeptin and GnRH neurons in the mediobasal hypothalamus of the male rhesus monkey (Macaca mulatta) as revealed by double immunofluorescence and confocal microscopy. Endocrinology 2008;149:4387-4395.

20 Smith JT, Coolen LM, Kriegsfeld LJ, Sari IP, Jaafarzadehshirazi MR, Maltby M, Bateman K, Goodman RL, Tilbrook AJ, Ubuka T, Bentley GE, Clarke IJ, Lehman MN: Variation in kisspeptin and RFamide-related peptide (RFRP) expression and terminal connections to gonadotropin-releasing hormone neurons in the brain: a novel medium for seasonal breeding in the sheep. Endocrinology 2008; 149:5770-5782.

21 Dumalska I, Wu M, Morozova E, Liu R, van den Pol A, Alreja M: Excitatory effects of the puberty-initiating peptide kisspeptin and group i metabotropic glutamate receptor agonists differentiate two distinct subpopulations of gonadotropin-releasing hormone neurons. J Neurosci 2008;28:8003-8013.

22 Pielecka-Fortuna J, Chu Z, Moenter SM: Kisspeptin acts directly and indirectly to increase gonadotropin-releasing hormone neuron activity and its effects are modulated by estradiol. Endocrinology 2008;149:1979-1986.

23 Matsui H, Takatsu Y, Kumano S, Matsumoto $\mathrm{H}$, Ohtaki T: Peripheral administration of metastin induces marked gonadotropin release and ovulation in the rat. Biochem Biophys Res Commun 2004;320:383-388.

24 Krajewski SJ, Burke MC, Anderson MJ, McMullen NT, Rance NE: Forebrain projections of arcuate neurokinin $\mathrm{B}$ neurons demonstrated by anterograde tract-tracing and monosodium glutamate lesions in the rat. Neuroscience 2010;166:680-697.

25 Kallo I, Vida B, Deli L, Molnar CS, Hrabovszky E, Caraty A, Ciofi P, Coen CW, Liposits Z: Co-localisation of kisspeptin with galanin or neurokinin $\mathrm{B}$ in afferents to mouse $\mathrm{GnRH}$ neurones. J Neuroendocrinol 2012;24:464476.

26 Hrabovszky E, Molnar CS, Sipos MT, Vida B, Ciofi P, Borsay BA, Sarkadi L, Herczeg L, Bloom SR, Ghatei MA, Dhillo WS, Kallo I, Liposits Z: Sexual dimorphism of kisspeptin and neurokinin $\mathrm{B}$ immunoreactive neurons in the infundibular nucleus of aged men and women. Front Endocrinol (Lausanne) 2011;2: 80.

27 Molnar CS, Vida B, Sipos MT, Ciofi P, Borsay BA, Racz K, Herczeg L, Bloom SR, Ghatei MA, Dhillo WS, Liposits Z, Hrabovszky E: Morphological evidence for enhanced kisspeptin and neurokinin B signaling in the infundibular nucleus of the aging man. Endocrinology 2012;153:5428-5439.

28 Navarro VM, Gottsch ML, Wu M, GarciaGaliano D, Hobbs SJ, Bosch MA, Pinilla L, Clifton DK, Dearth A, Ronnekleiv OK, Braun
RE, Palmiter RD, Tena-Sempere M, Alreja M, Steiner RA: Regulation of NKB pathways and their roles in the control of kiss1 neurons in the arcuate nucleus of the male mouse. Endocrinology 2011;152:4265-4275.

29 Gaskins GT, Glanowska KM, Moenter SM: Activation of neurokinin 3 receptors stimulates $\mathrm{GnRH}$ release in a location-dependent but kisspeptin-independent manner in adult mice. Endocrinology 2013;154:3984-3989.

30 Dudas B, Merchenthaler I: Close juxtapositions between LHRH immunoreactive neurons and substance $\mathrm{P}$ immunoreactive axons in the human diencephalon. J Clin Endocrinol Metab 2002;87:2946-2953.

31 Tsuruo Y, Kawano H, Hisano S, Kagotani Y, Daikoku S, Zhang T, Yanaihara N: substance P-containing neurons innervating LHRHcontaining neurons in the septo-preoptic area of rats. Neuroendocrinology 1991;53:236245.

32 Matsuyama S, Ohkura S, Mogi K, Wakabayashi Y, Mori Y, Tsukamura H, Maeda K, Ichikawa M, Okamura H: Morphological evidence for direct interaction between kisspeptin and gonadotropin-releasing hormone neurons at the median eminence of the male goat: an immunoelectron microscopic study. Neuroendocrinology 2011;94:323-332.

33 Ciofi P, Leroy D, Tramu G: Sexual dimorphism in the organization of the rat hypothalamic infundibular area. Neuroscience 2006; 141:1731-1745.

34 d'Anglemont de Tassigny X, Fagg LA, Carlton MB, Colledge WH: Kisspeptin can stimulate gonadotropin-releasing hormone $(\mathrm{GnRH})$ release by a direct action at $\mathrm{GnRH}$ nerve terminals. Endocrinology 2008; 149: 3926-3932.

35 Navarro VM, Castellano JM, Fernandez-Fernandez R, Tovar S, Roa J, Mayen A, Barreiro ML, Casanueva FF, Aguilar E, Dieguez C, Pinilla L, Tena-Sempere M: Effects of kiss-1 peptide, the natural ligand of GPR54, on follicle-stimulating hormone secretion in the rat. Endocrinology 2005;146:1689-1697.

- 36 Shahab M, Mastronardi C, Seminara SB, Crowley WF, Ojeda SR, Plant TM: Increased hypothalamic GPR54 signaling: a potential mechanism for initiation of puberty in primates. Proc Natl Acad Sci U S A 2005; 102: 2129-2134.

37 Dhillo WS, Chaudhri OB, Patterson M, Thompson EL, Murphy KG, Badman MK, McGowan BM, Amber V, Patel S, Ghatei MA, Bloom SR: Kisspeptin-54 stimulates the hypothalamic-pituitary gonadal axis in human males. J Clin Endocrinol Metab 2005;90: 6609-6615.

38 Dhillo WS, Chaudhri OB, Thompson EL, Murphy KG, Patterson M, Ramachandran R, Nijher GK, Amber V, Kokkinos A, Donaldson M, Ghatei MA, Bloom SR: Kisspeptin-54 stimulates gonadotropin release most potently during the preovulatory phase of the menstrual cycle in women. J Clin Endocrinol Metab 2007;92:3958-3966. 
39 Herde MK, Geist K, Campbell RE, Herbison AE: Gonadotropin-releasing hormone neurons extend complex highly branched dendritic trees outside the blood-brain barrier. Endocrinology 2011;152:3832-3841.

40 Rasmussen DD, Gambacciani M, Swartz W, Tueros VS, Yen SS: Pulsatile gonadotropinreleasing hormone release from the human mediobasal hypothalamus in vitro: opiate receptor-mediated suppression. Neuroendocrinology 1989;49:150-156.

-41 Rasmussen DD: Episodic gonadotropin-releasing hormone release from the rat isolated median eminence in vitro. Neuroendocrinology 1993;58:511-518.

-42 Cheng G, Coolen LM, Padmanabhan V, Goodman RL, Lehman MN: The kisspeptin/ neurokinin $\mathrm{B} /$ dynorphin (KNDy) cell population of the arcuate nucleus: sex differences and effects of prenatal testosterone in sheep. Endocrinology 2010;151:301-311.

-43 Hokfelt T, Pernow B, Nilsson G, Wetterberg L, Goldstein M, Jeffcoate SL: Dense plexus of substance $\mathrm{P}$ immunoreactive nerve terminals in eminentia medialis of the primate hypothalamus. Proc Natl Acad Sci U S A 1978;75: 1013-1015.

-44 King JC, Anthony EL: LHRH neurons and their projections in humans and other mammals: species comparisons. Peptides 1984; 5(suppl 1):195-207.

45 Duvernoy H, Koritke JG, Monnier G: Vascularization of the posterior tuber in man and its relation to the tuber-hypophyseal vasculature. J Neurovisc Relat 1971;32:112-142.

46 Mihaly E, Fekete C, Lechan RM, Liposits Z: Corticotropin-releasing hormone-synthesizing neurons of the human hypothalamus receive neuropeptide Y-immunoreactive innervation from neurons residing primarily outside the infundibular nucleus. J Comp Neurol 2002;446:235-243.

-47 Schnell SA, Staines WA, Wessendorf MW: Reduction of lipofuscin-like autofluorescence in fluorescently labeled tissue. J Histochem Cytochem 1999;47:719-730.

48 Liposits Z, Setalo G, Flerko B: Application of the silver-gold intensified $3,3^{\prime}$-diaminobenzidine chromogen to the light and electron microscopic detection of the luteinizing hormone-releasing hormone system of the rat brain. Neuroscience 1984;13:513-525.
49 Ramaswamy S, Seminara SB, Ali B, Ciofi P, Amin NA, Plant TM: Neurokinin B stimulates $\mathrm{GnRH}$ release in the male monkey ( $\mathrm{Ma}$ caca mulatta) and is colocalized with kisspeptin in the arcuate nucleus. Endocrinology 2010;151:4494-4503.

50 Conti F, De Biasi S, Fabri M, Abdullah L, Manzoni T, Petrusz P: Substance P-containing pyramidal neurons in the cat somatic sensory cortex. J Comp Neurol 1992;322:136148.

51 Dudas B, Mihaly A, Merchenthaler I: Topography and associations of luteinizing hormone-releasing hormone and neuropeptide $\mathrm{Y}$-immunoreactive neuronal systems in the human diencephalon. J Comp Neurol 2000; 427:593-603.

52 Hrabovszky E, Liposits Z: Afferent neuronal control of type-1 gonadotropin releasing hormone neurons in the human. Front Endocrinol (Lausanne) 2013;4:130.

53 Ramaswamy S, Gibbs RB, Plant TM: Studies of the localisation of kisspeptin within the pituitary of the rhesus monkey (Macaca mulatta) and the effect of kisspeptin on the release of non-gonadotropic pituitary hormones. J Neuroendocrinol 2009;21:795-804.

54 Clarke I, Jessop D, Millar R, Morris M, Bloom S, Lightman S, Coen CW, Lew R, Smith I: Many peptides that are present in the external zone of the median eminence are not secreted into the hypophysial portal blood of sheep. Neuroendocrinology 1993;57:765-775.

55 Fuxe K, Andersson K, Harfstrand A, Agnati LF, Eneroth P, Janson AM, Vale W, Thorner M, Goldstein M: Medianosomes as integrative units in the external layer of the median eminence. Studies on GRF/catecholamine and somatostatin/catecholamine interactions in the hypothalamus of the male rat. Neurochem Int 1986;9:155-170.

56 Kawakami SI, Hirunagi K, Ichikawa M, Tsukamura H, Maeda KI: Evidence for terminal regulation of $\mathrm{GnRH}$ release by excitatory amino acids in the median eminence in female rats: a dual immunoelectron microscopic study. Endocrinology 1998;139:1458-1461.
57 Setalo G, Vigh S, Schally AV, Arimura A, Flerko B: Immunohistological study of the origin of LH-RH-containing nerve fibers of the rat hypothalamus. Brain Res 1976;103:597602 .

58 Lin W, McKinney K, Liu L, Lakhlani S, Jennes L: Distribution of vesicular glutamate transporter-2 messenger ribonucleic acid and protein in the septum-hypothalamus of the rat. Endocrinology 2003;144:662-670.

59 Kawakami S, Ichikawa M, Murahashi K, Hirunagi K, Tsukamura H, Maeda K: Excitatory amino acids act on the median eminence nerve terminals to induce gonadotropin-releasing hormone release in female rats. Gen Comp Endocrinol 1998;112:372382.

60 Hrabovszky E, Turi GF, Kallo I, Liposits Z: Expression of vesicular glutamate transporter-2 in gonadotropin-releasing hormone neurons of the adult male rat. Endocrinology 2004;145:4018-4021.

61 Tsuruo Y, Kawano H, Kagotani Y, Hisano S, Daikoku S, Chihara K, Zhang T, Yanaihara N: Morphological evidence for neuronal regulation of luteinizing hormone-releasing hormone-containing neurons by neuropeptide $\mathrm{Y}$ in the rat septo-preoptic area. Neurosci Lett 1990;110:261-266.

62 Li C, Chen P, Smith MS: Morphological evidence for direct interaction between arcuate nucleus neuropeptide Y (NPY) neurons and gonadotropin-releasing hormone neurons and the possible involvement of NPY Y1 receptors. Endocrinology 1999;140: 5382-5390.

63 Kalra SP, Fuentes M, Fournier A, Parker SL, Crowley WR: Involvement of the Y-1 receptor subtype in the regulation of luteinizing hormone secretion by neuropeptide $\mathrm{Y}$ in rats. Endocrinology 1992;130:3323-3330.

-64 Keen KL, Wegner FH, Bloom SR, Ghatei MA, Terasawa E: An increase in kisspeptin-54 release occurs with the pubertal increase in luteinizing hormone-releasing hormone-1 release in the stalk-median eminence of female rhesus monkeys in vivo. Endocrinology 2008; 149:4151-4157.

65 Mikkelsen JD, Bentsen AH, Ansel L, Simonneaux V, Juul A: Comparison of the effects of peripherally administered kisspeptins. Regul Pept 2009;152:95-100. 